\title{
Regulation of 3-hydroxybutyrate formation and secretion of very-low- density-lipoprotein triacylglycerol by perfused livers from fed and starved rats
}

\author{
Mary E. LAKER and Peter A. MAYES \\ Department of Physiology and Biochemistry, Royal Veterinary College, London NW1 OTU, U.K.
}

(Received 7June 1982/Accepted 18 June 1982)

\begin{abstract}
Acetoacetate was the sole ketone body formed when livers from starved rats were perfused with minimal concentrations of non-esterified fatty acid. Absence of 3-hydroxybutyrate was related to a low substrate potential, which caused a more oxidized redox state and a decreased [ATP]/[ADP] ratio. Only under conditions of comparable non-esterified fatty acid uptake was lipoprotein triacylglycerol production inversely related to ketogenesis.
\end{abstract}

Preliminary studies indicated that, under certain conditions, perfused rat livers produce mainly acetoacetate with only minimal amounts of 3hydroxybutyrate. Any theory put forward to account for the regulation of ketogenesis must explain this observation. Therefore, perfusions of livers from fed or starved rats, at either minimal or increased concentrations of non-esterified fatty acid, were carried out to define the conditions necessary for this type of ketogenesis and to delineate the controlling mechanism. As an inverse relationship between ketogenesis and VLD-lipoprotein formation has been reported (Mayes \& Felts, 1967; Ide \& Ontko, 1981), the rates of VLD-lipoprotein triacylglycerol secretion were also determined simultaneously.

\section{Materials and methods}

Male Wistar rats (M.R.C. Porton strain) were kept under constant temperature $\left(25^{\circ} \mathrm{C}\right)$ and daylength $(18 \mathrm{~h})$ on Diet 86 (E. Dixon, Ware, Herts., U.K.) for a minimum of 3 weeks before experimentation. Liver donors weighed $345-360 \mathrm{~g}$; some donors were starved for $24 \mathrm{~h}$ before use. Livers were perfused in situ by a modification of the method of Mayes \& Felts (1966). The perfusate was whole rat blood, defibrinated and dialysed, to remove vasoconstrictors, for $24 \mathrm{~h}$ against bicarbonate buffer (Krebs \& Henseleit, 1932). This contained half the specified concentration of $\mathrm{Ca}^{2+}$, plasma amino acids to give concentrations recorded by Bloxham (1971) for fed or starved rats, and glucose at 16.6 or $5.5 \mathrm{~mm}$ for livers from fed or starved rats respectively.

Abbreviation used: VLD lipoprotein, very-low-density lipoprotein $(d<1.006)$.
Each liver donor was anaesthetized with sodium pentobarbital $(60 \mathrm{mg} / \mathrm{kg}$ body wt.; Abbott Laboratories, Queenborough, Kent, U.K.) and the liver was connected, via the cannulated hepatic portal vein, to a system containing $80 \mathrm{ml}$ of recirculating dialysed blood preheated to $37^{\circ} \mathrm{C}$ in a thermostatic cabinet. During an initial $10 \mathrm{~min}$ period the liver temperature was stabilized at $37 \pm 0.1^{\circ} \mathrm{C}$. The $\mathrm{pO}_{2}$ of the inflowing blood, minitored by an oxygen-electrode (Radiometer, Copenhagen, Denmark), was adjusted to $12-31 \mathrm{kPa}$ (90$100 \mathrm{mmHg}$ ) by varying the composition of the mixture of $\mathrm{O}_{2} / \mathrm{CO}_{2}(19: 1)$ and air $/ \mathrm{CO}_{2}(19: 1)$ used for oxygenation. The rate of blood flow through the liver was set at $12 \mathrm{ml} / \mathrm{min}$. After this period the perfusate glucose concentrations were 10.2 and $4.0 \mu \mathrm{mol} / \mathrm{ml}$ in perfusions of livers from fed and starved rats respectively. Oleic acid (Sigma Chemical Co., Poole, Dorset, U.K.) complexed to bovine serum albumin (Armour Pharmaceutical Co., Eastbourne, Sussex, U.K.) in $0.9 \% \mathrm{NaCl}$ was infused into the perfusate of some livers to maintain a non-esterified fatty acid concentration of approx. $1.0 \mu \mathrm{mol} / \mathrm{ml}$ for an experimental period of $40 \mathrm{~min}$. Albumin alone in $0.9 \% \mathrm{NaCl}$ was infused in an equal number of other perfusions.

Samples of blood perfusate were withdrawn at the beginning and end of the experimental period and acetoacetate and $D(-)-3$-hydroxybutyrate concentrations were determined. Serum was prepared by low-speed centrifugation and the content of nonesterified fatty acids was assayed. VLD lipoproteins were separated from serum by ultracentrifugation and triacylglycerol was measured in chloroform/ methanol $(2: 1, \mathrm{v} / \mathrm{v})$ extracts. The analytical procedures have been described in detail previously 
(Laker \& Mayes, 1979, 1981). Eight livers from fed rats were perfused, four with and four without infusion of oleate. These were compared with eight livers from $24 \mathrm{~h}$-starved rats, four perfused with and four perfused without oleate infusion. While still under perfusion, livers were freeze-clamped and adenine nucleotides were determined by the methods of Lamprecht \& Trautschold (1974) and Jaworek et al. (1974). Results are reported as means \pm S.E.M. and were analysed statistically by Student's $t$ test.

\section{Results and discussion}

The average weight of the livers perfused from fed rats was $12.06 \pm 0.38 \mathrm{~g}$, compared with $9.12 \pm 0.33 \mathrm{~g}$ of livers from $24 \mathrm{~h}$-starved rats. Livers from fed rats produced $0.83 \pm 0.08 \mathrm{ml}$ of bile $/ \mathrm{h}$, a significantly greater rate $(0.01<P<0.05)$ than the value of $0.63 \pm 0.04$ produced by livers from starved rats. However, the unit rates were similar $(68.2 \pm 5.7$ and $69.3 \pm 7.1 \mu \mathrm{l} / \mathrm{h}$ per $\mathrm{g}$ respectively). The glycogen content of perfused livers from fed rats was $3.09 \pm 0.45 \%$, whereas that of livers from starved rats was minimal $(0.014 \pm 0.004 \%)$. There were no significant effects of oleate infusion on any of these parameters.

\section{Extraction of non-esterified fatty acid}

Oleate infusion caused the serum non-esterified fatty acid concentration to increase and stabilize at $1.01 \pm 0.01$ and $1.11 \pm 0.02 \mu \mathrm{mol} / \mathrm{ml}$ in perfusates of livers from fed and starved rats respectively. The difference, which was significant $(P<0.001)$, indicated that the fractional extraction of non-esterified fatty acids by the relatively smaller livers from starved rats was less $(43.1 \pm 0.6 \%$ compared with $48.2 \pm 1.0 \%, 0.001<P<0.01)$. This decreased uptake by livers from starved rats may be due to their reduced mass but may also result from their greater intracellular non-esterified fatty acid concentration (Poledne \& Mayes, 1970), which would decrease the concentration gradient from serum to hepatocyte and therefore the fractional extraction from the blood. In the absence of infused oleate, the serum non-esterified fatty acid concentration declined to $0.27 \pm 0.02 \mu \mathrm{mol} / \mathrm{ml}$ in perfusions of livers from fed rats and to $0.23 \pm 0.02$ in perfusions of livers from starved rats.

\section{Acetoacetate and 3-hydroxybutyrate production}

In the presence of an oleate infusion, livers from fed rats produced $74 \mu \mathrm{mol}$ of total ketone bodies, compared with $322 \mu \mathrm{mol}$ produced by livers from starved animals, a rate of $8.8 \pm 0.9$ and $55.0 \pm 3.6 \mu \mathrm{mol} / \mathrm{h}$ per $\mathrm{g}$ respectively $(P<0.001)$. In the absence of oleate infusion the rates were correspondingly less (Fig. 1), 6.5 \pm 0.8 and $8.2 \pm 1.1 \mu \mathrm{mol} / \mathrm{h}$ per $\mathrm{g}$, in livers from fed and starved rats respectively. When oleate was infused, 3hydroxybutyrate accounted for $44.4 \%$ of the total ketone bodies produced by livers from fed rats and $58.4 \%$ of those produced by livers from starved rats. However, in the absence of infused non-esterified fatty acid, livers from fed rats again produced $44.0 \%$ of total ketone bodies as 3-hydroxybutyrate but livers from starved rats produced none (Fig. 1), the total ketone body production being entirely accounted for by acetoacetate. As a consequence, the perfusate [3-hydroxybutyrate]/[acetoacetate] ratio (Fig. 1) maintained by liver from fed rats in the presence of oleate was only marginally greater than that in its absence, but livers from starved rats exhibited a much more oxidized ratio in the absence of infused oleate $(P<0.001)$ and a more reduced ratio in its presence $(0.001<P<0.01)$.

Although this is the first report of a complete

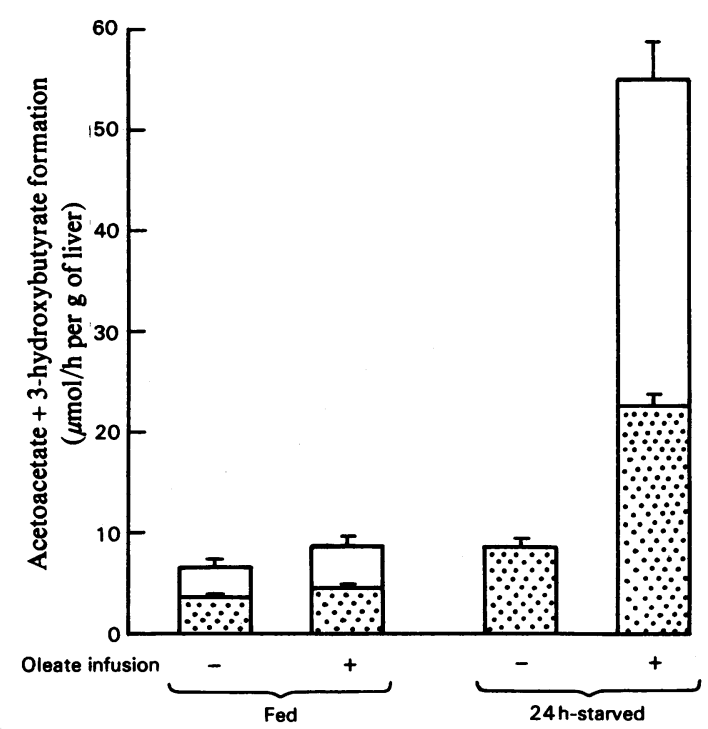

Fig. 1. Effect of the nutritional state and the concentration of non-esterified fatty acids on acetoacetate and 3-hydroxybutyrate formation by perfused livers Livers from fed or $24 \mathrm{~h}$-starved rats were perfused with whole blood as described in the text. Half of the perfusions received a continuous infusion of oleate complexed to albumin, which increased the serum non-esterified fatty acid concentration from 0.25 to $1.06 \mu \mathrm{mol} / \mathrm{ml}$. Results are expressed as means \pm S.E.M. (represented by the bars) of four perfusions. a, Acetoacetate; $\square$, 3-hydroxybutyrate. Net formation of ketone bodies was measured over the experimental period 0-40 min. The [3-hydroxybutyrate]/[acetoacetate] ratio at the end of this period in perfusates of livers from fed rats was $0.90 \pm 0.06$ in the absence of oleate infusion and $1.18 \pm 0.14$ in its presence; the corresponding values for perfusates of livers from starved rats were $0.31 \pm 0.05$ and $1.41 \pm 0.09$. 
absence of 3-hydroxybutyrate production in an intact liver system, trends revealed in other investigations support present results. Non-esterified fatty acids, when infused into starved perfused livers (Williamson et al., 1969) or added to isolated starved hepatocytes (Ontko, 1972; Siess et al., 1982) increased the [3-hydroxybutyrate]/[acetoacetate] ratio. In the absence of non-esterified fatty acids, the ratio was greater in perfused livers from fed rats compared with livers from starved rats (Brunengraber et al., 1973).

ATP concentrations in perfused livers from all fed rats and from starved rats infused with oleate averaged $2.95 \pm 0.04 \mu \mathrm{mol} / \mathrm{g}$ of liver and the concentration in perfused livers from starved rats without oleate infusion was $2.55 \pm 0.27 \mu \mathrm{mol} / \mathrm{g}$ of liver. The $[\mathrm{ATP}] /[\mathrm{ADP}]$ ratio of the latter group of livers, which did not produce 3-hydroxybutyrate, was $4.25 \pm 0.17$, significantly less $(0.001<P<0.01)$ than the mean value of $5.36 \pm 0.24$ found in all other livers. A relationship between the phosphorylation potential and fatty acid oxidation was also observed by Shepherd et al. (1965), who showed in isolated mitochondria that palmitoyl-CoA was oxidized to neither the rate of hepatic lipolysis of liver acyladdition of ATP the main product was 3-hydroxybutyrate.

Present results are in keeping with, and may be explained by, the hypothesis of Mayes \& Felts (1967) that ketogensis is regulated by the energy (ATP) requirements of the liver (see also Mayes, 1970; Flatt, 1972; Mayes \& Laker, 1981). Thus in livers from the starved rats, in the presence of an increased concentration of non-esterified fatty acid (i.e. a high substrate potential), fatty acids undergoing $\beta$-oxidation surplus to ATP requirements are diverted away from the tricarboxylic acid cycle into the non-ATP-producing pathway of ketogenesis, particularly to 3-hydroxybutyrate formation, which is in effect an ATP consuming reaction, since reducing equivalents are taken up during the conversion from acetoacetate. Under these con- ditions, the mitochondrial redox state is more reduced, as indicated by the increased [3-hydroxybutyrate]/[acetoacetate] ratio, and the [ATP]/ [ADP] ratio is maintained. When the supply of non-esterified fatty acids from the perfusate is minimal, livers from starved rats are probably at a low substrate potential. Not only is their [ATP]/ [ADP] ratio decreased but also their $\mathrm{O}_{2}$ consumption during perfusion diminishes, unless nonesterified fatty acids or lactate are provided (P. A. Mayes, unpublished work), demonstrating that neither the rate of hepatic lipolysis of liver acylglycerols nor the glucose present in the perfusate are sufficient to sustain oxidative metabolism. Thus, when the concentration of non-esterified fatty acid passing through livers from starved rats is minimal, acetoacetate rather than the more energy-rich 3-hydroxybutyrate is formed and the mitochondrial redox state, as indicated by the [3-hydroxybutyrate]/[acetoacetate] ratio, is more oxidized. The production of 3-hydroxybutyrate, as well as acetoacetate, by livers from fed rats perfused with a minimal concentration of non-esterified fatty acid is due, most likely, to the availability of glycogen as a fuel, which confers a high substrate potential and, therefore, a more reduced redox state on the liver.

\section{VLD-lipoprotein secretion and ketogenesis}

An inverse relationship between ketogenesis and VLD-lipoprotein secretion by the perfused liver has been described, which reflects the balance between oxidation and esterification of fatty acids (Mayes \& Felts, 1967). Recently, an increase in VLD-lipoprotein triacylglycerol secretion was found to result from the inhibition of fatty acid oxidation and ketogenesis, indicating that VLD-lipoprotein secretion is controlled by the activity of the oxidation pathway (Ide \& Ontko, 1981). However, present results demonstrate that the inverse relationship does not hold under all conditions. Livers from fed rats (Table 1) secreted $50 \mu \mathrm{mol}$ of VLD-lipoprotein

Table 1. Effect of nutritional state and the concentration of non-esterified fatty acids on the secretion of triacylglycerol from perfused livers

Livers from fed or $24 \mathrm{~h}$-starved rats were perfused with whole blood as described in the text. Half of the perfusions received a continuous infusion of oleate complexed to albumin, which increased the serum non-esterified fatty acid concentration from 0.25 to $1.06 \mu \mathrm{mol} / \mathrm{ml}$. Results are expressed as means \pm S.E.M. of four perfusions. The significance of differences from group (A) was evaluated by Student's $t$ test: ${ }^{*}, 0.01<P<0.05 ;{ }^{* *}, 0.001<P<0.01$; ***, $P<0.001$.

Triacylglycerol fatty acids secreted in VLD lipoproteins $(\mu \mathrm{mol} / \mathrm{h})$

\begin{tabular}{|c|c|c|c|}
\hline \multicolumn{2}{|c|}{ Livers from fed rats } & \multicolumn{2}{|c|}{ Livers from $24 \mathrm{~h}$-starved rats } \\
\hline $\begin{array}{l}\text { Without oleate infusion } \\
\text { (A) }\end{array}$ & $\begin{array}{l}\text { With oleate infusion } \\
\text { (B) }\end{array}$ & $\begin{array}{l}\text { Without oleate infusion } \\
\text { (C) }\end{array}$ & $\begin{array}{l}\text { With oleate infusion } \\
\text { (D) }\end{array}$ \\
\hline $\begin{array}{r}50.25 \pm 3.51 \\
4.37+0.17\end{array}$ & $\begin{array}{r}110.02 \pm 4.93^{* * *} \\
8.70+0.40^{* * *}\end{array}$ & $\begin{array}{c}22.03 \pm 4.41^{* *} \\
2.42+0.59^{*}\end{array}$ & $\begin{array}{c}29.43 \pm 7.28^{*} \\
3.36+0.82\end{array}$ \\
\hline
\end{tabular}

(a) Per liver

(b) Per g of liver
$110.02 \pm 4.93^{* * *}$

$10+0.40^{* * *}$

$2.42 \pm 0.59^{*}$

$3.36 \pm 0.82$

Vol. 206 
triacylglycerol fatty acid per hour with minimal ketogenesis. When non-esterified fatty acids were infused, triacylglycerol secretion and ketogenesis both increased. Similarly, in livers from starved rats, infusion of non-esterified fatty acid caused a highly significant increase in ketogenesis accompanied by a slight increase, rather than a diminution, in triacylglycerol secretion. Nevertheless, when livers from fed rats are compared with livers from starved rats into which oleate is infused at the same rate (Table 1, Fig. 1), there is a marked inverse relationship between ketogenesis and VLD-lipoprotein triacylglycerol secretion, confirming previous observations (Mayes \& Felts, 1967). Thus, the inverse relationship operates only when ketogenesis and VLDlipoprotein secretion are compared under conditions in which the uptake of hepatic non-esterified fatty acid is similar.

These results and conclusions indicate that the plasma non-esterified fatty acid concentration should be taken into consideration when correlations between ketogenesis and VLD-lipoprotein secretion are made from data obtained in vivo.

The skilled technical assistance of T. Murdoch and $M$. Avella and the support of the Medical Research Council is acknowledged.

\section{References}

Bloxham, D. L. (1971) Br.J. Nutr. 27, 233-259

Brunengraber, H., Boutry, M. \& Lowenstein, J. M. (1973) J. Biol. Chem. 248, 2656-2669
Flatt, J. P. (1972) Diabetes 21, 50-53

Ide, T. \& Ontko, J. A. (1981) J. Biol. Chem. 256, 10247-10255

Jaworek, D., Gruber, W. \& Bergmeyer, H. U. (1974) in Methods of Enzymatic Analysis (Bergmeyer, H. U., ed.), pp. 2127-2131, Academic Press, London

Krebs, H. A. \& Henseleit, K. (1932) Hoppe-Seyler's Z. Physiol. Chem. 210, 33-66

Laker, M. E. \& Mayes, P. A. (1979) Biochem. Pharmacol. 28, 2813-2827

Laker, M. E. \& Mayes, P. A. (1981) Biochem. J. 196, 247-255

Lamprecht, W. \& Trautschold, I. (1974) in Methods of Enzymatic Analysis (Bergmeyer, H. U., ed.), pp. 2101-2110, Academic Press, London

Mayes, P. A. (1970) in Adopose Tissue Regulation and Metabolic Functions (Jeanrenaud, B. \& Hepp, D., eds.), pp. 186-195, Academic Press, New York and London

Mayes, P. A. \& Felts, J. M. (1966) Proc. Eur. Soc. Study Drug Toxicity 7, 16-29

Mayes, P. A. \& Felts, J. M. (1967) Nature (London) 215, 716-718

Mayes, P. A. \& Laker, M. E. (1981) Biochem. Soc. Trans. 9, 339-341

Ontko, J. A. (1972) J. Biol. Chem. 247, 1788-1800

Poledne, R. \& Mayes, P.A. (1970) Biochem. J. 119, 47p-48P

Shepherd, D., Yates, D. W. \& Garland, P. B. (1965) Biochem. J. 97. 38c-40C

Siess, E. A., Kientsch-Engel, R. I. \& Wieland, O. H. (1982) Eur. J. Biochem. 121, 493-499

Williamson, J. R., Scholz, R. \& Browning, E. T. (1969) J. Biol. Chem. 244, 4617-4627 